\title{
Nitric Oxide Scavenging Activity of Bioactive Compounds Present in Methanolic Extract of Morchella esculenta
}

\author{
D. R. Baba ${ }^{1}$, P. M. Junaid ${ }^{2}$, F. Khan ${ }^{3}$, R. $\operatorname{Singh}^{4}$ \\ ${ }^{1,2,4}$ Department of Life Sciences, Govt. M.V.M, Barkatullah University , Bhopal, India \\ ${ }^{3}$ Department of Botany, Govt. College Nasrullah Gung, Sehore, India \\ *Corresponding Author: danishbaba009@gmail.com, Ph. No. +917889365060
}

Available online at: www.isroset.org

Received: 06/Oct/2018, Accepted: 20/Oct/2018, Online: 30/Oct/2018

\begin{abstract}
Morchella esculenta is commonly known as morel, common morel, true morel, yellow morel, sponge morel and morel mushroom [1]. It is one of the most easily recognized of all the edible mushrooms and highly sought after. Morchella mushroom is one of the costliest edible fungi in the world. Morchella esculenta is in economically important mushroom commonly known as "Guchhi" in India. In India, the presence of Morchella is reported from Himachal Pradesh, Uttar Pradesh and Jammu and Kashmir [2]. It has been reported that the morel species are good to minimize the oxidative damage in organisms that occur in several chronic diseases. Moreover, these morel species can be used to find new antimicrobials overlapping the resistance of bacteria to first choice antibiotics. The compounds like Phenol, Tocopherol and organic acids are considered to be the most responsible for antioxidant activity of mushrooms [3][4]. Methanol extract of Morchella esculenta was screened to evaluate free radical scavenging effect. The extract exhibited significant reducing power and free radical scavenging effect on nitric oxide radicals. This antioxidant activity was concentration dependent which were compared with standard antioxidants such as ascorbic acid. The highest free radical scavenging effect of the extract was observed at concentration of $100 \mu \mathrm{g} / \mathrm{ml}$ and the $\mathrm{IC}_{50}$ value of extract was $49.8821 \mu \mathrm{g} / \mathrm{ml}$.
\end{abstract}

Keywords: Nitric oxide scavenging, Morchella esculenta, Methanolic Extract, Antioxidant activity

\section{INTRODUCTION}

Oxygen is an important element for life. Oxidative properties of oxygen play a vital role in many biological processes. Reactive oxygen species (ROS) are an entire class of highly reactive molecules derived from the metabolism of oxygen. At normal physiological concentrations ROS are required for cellular activities, however, at higher concentrations, ROS can cause extensive damage to cells and tissues, during infections and various degenerative disorders, such as cardiovascular disease, aging, and neurodegenerative diseases like Alzheimer's disease, mutations and cancer [5]. Antioxidants, synthetic or natural, can be effective to help the human body in reducing oxidative damage by ROS [6]. However, at the present time suspected that synthetic antioxidants such as buthylated hydroxyl anisole (BHA), buthylated hydroxyl toluene (BHT), tert-butyl hydroquinone (TBHQ) and propyl gallate (PG) have toxic and carcinogenic effects [7]. Therefore, the development and utilization of more effective antioxidants of natural origins are desired. In recent years, the antioxidant properties of numerous plants, lichens and mushrooms have been widely reported. In order to find new natural sources of antioxidants, our attention was focused on mushrooms. Mushrooms possess high contents of qualitative protein, crude fibre, minerals and vitamins. Apart from their nutritional potentials, mushrooms are also sources of physiologically beneficial bioactive substances that promote good health. They produce a wide range of secondary metabolites with high therapeutic value. Health promoting properties, e.g. antioxidant, antimicrobial, anticancer, cholesterol lowering and immune stimulatory effects, have been reported for some species of mushrooms. Both fruiting bodies and the mycelium contain compounds with wide ranging antioxidant and antimicrobial activities [8][9][10][11].

Nitric Oxide is an important bio regulatory molecule, which has a number of physiological effects including control of blood pressure, neural signal transduction, platelet function, antimicrobial and antitumor activity [12]. Nitrous Oxide also shows toxic property after reaction with oxygen and superoxide radicals. The reaction products are able to cause much cellular damage [13]. The Fruiting body of Morchella esculenta begins as a tightly compressed, greyish sponge with lighter ridges and expands to form a large yellowish 
sponge with large pits and ridges raised on a large white stem. Traditionally the mushrooms are used as medicine due to their antioxidant activity and play important role to relieve many diseases. The present study aims to spectrophotometric quantification of nitric oxide radical scavenging activity in the methanol extract of Morchella esculenta.

\section{RELATED WORK}

Turkoglu A. et al., (2006) worked on "Antioxidant and antimicrobial activities of Morchella conica Pers."

Sandrina A. Heleno et al., (2013) worked "A comparative study of chemical composition, antioxidant and antimicrobial properties of Morchella esculenta (L.) Pers. from Portugal and Serbia"

Maryam Ajmal et al., (2015) studied on "Morchella Esculenta: An edible and health beneficial mushroom"

Fatih Kalyoncu et al., (2010) researched on the "Antimicrobial and Antioxidant Activities of Mycelia of 10 Wild Mushroom Species"

\section{METHODOLOGY}

\section{Material and Method:}

\section{Sample collection and processing:}

The sample of Morchella esculenta was collected from the different areas of district Kulgam of Jammu and Kashmir. The collected sample was observed on the basis of morphological and other phenotypic parameters recorded in fresh sample. The authentication of the collected sample was done by Center for Microbiology and Bio-Technology $(C M B T)$ Bhopal. The mushroom sample was then shed dried and crushed to obtain powder.

\section{Extraction:}

The process of extraction of Morchella esculenta was carried out by Soxhlet extractor. The dried and powdered sample of Morchella esculenta was weighed and extracted with methanol in a Soxhlet apparatus. The extraction was done for 72 hours. The extract was then placed in a rotatory evaporator for evaporation and the dried extract was stored in a clean and air tight glass container for further use.

\section{Scavenging of nitric oxide radicals:}

Sodium nitroprusside in aqueous solution at physiological $\mathrm{pH}$ spontaneously generates Nitrite oxide which interacts with oxygen to produce Nitrite ions, which can be measured at $550 \mathrm{~nm}$ by spectrophotometer in the presence of Griess reagent.

Reagents and chemicals:

$5 \mathrm{mM}$ Sodium Nitroprusside, Griess reagent $(1 \%$ Sulphanilamide, $0.1 \% \mathrm{~N}$ 1-naphthylethylenediamine, $2 \%$ Orthophosphoric acid), Phosphate buffer (pH- 7.4)

\section{Procedure:-}

Morchella esculenta extract was dissolved in distilled water for this quantification. Sodium Nitroprusside $(5 \mathrm{mM})$ in standard phosphate buffer saline $(0.025 \mathrm{~m}, \mathrm{pH} 7.4)$ was incubated with different concentration of methanol extract and tubes were incubated at $29^{\circ} \mathrm{C}$ for 3 hours. Control experiment without the test compounds but with equivalent amount of buffer was conducted in an identical manner. After 3 hours incubated samples were diluted with $1 \mathrm{ml}$ of Griess reagents. The absorbance of the color developed during diazotization of Nitrite with Sulphanilamide and its subsequent coupling with Napthylethylenediaminehydrochloride was observed at $550 \mathrm{~nm}$ on spectrophotometer. Same procedure was done with ascorbic acid which was standard in comparison to methanol extract.

\section{RESULTS AND DISCUSSION}

Nitric oxide is a potent pleiotropic inhibitor of physiological processes such as smooth muscle relaxation, neuronal signaling, and inhibition of platelet aggregation and regulation of cell mediated toxicity [14]. In addition to reactive oxygen species, nitric oxide is also implicated in inflammation, cancer and other pathological conditions [15]. Nitric Oxide is known to be a ubiquitous free-radical moiety, which is distributed in tissues or organ systems and is supposed to have a vital role in neuromodulator or as a neurotransmitter in the CNS [16]. However, Morchella esculenta treatment significantly attenuated the colchicine'sinduced oxidative stress. Beside tri-terpenoids and essential oils, Morchella esculenta has also been reported to contain numerous flavonoids, phenols, alkaloids, tannins, and proteins etc. which are the major contributors in particular to the anti-oxidative activity of Morchella esculenta. It has been recently indicated to show free radical scavenging activities. The methanol extract of Morchella esculenta showed maximum activity of $50 \%$ respectively at $100 \mu \mathrm{g} / \mathrm{ml}$ and also showed the $\mathrm{IC}_{50}$ value of $49.8821 \mu \mathrm{g} / \mathrm{ml}$.

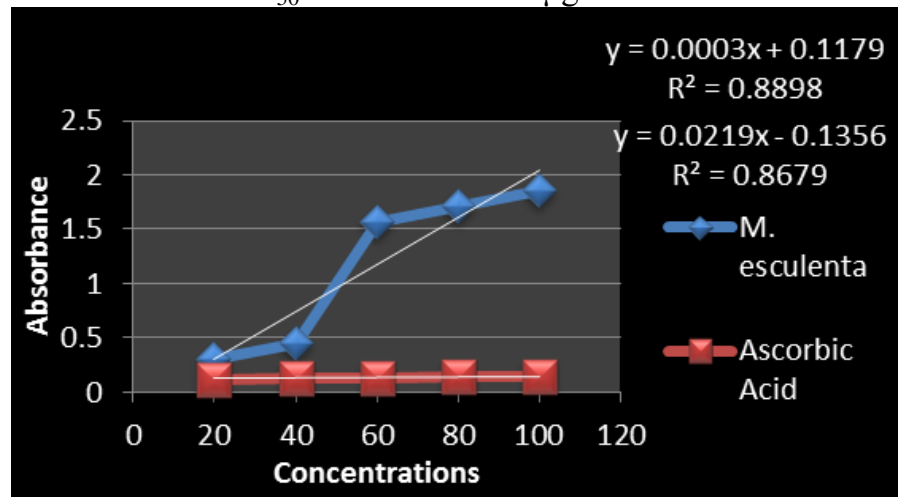

Figure-1 Nitric oxide scavenging assay of ascorbic acid and methanol extract

\section{CONCLUSION AND FUTURE SCOPE}

The present study suggests that the methanol extract of Morchella esculenta mushroom have many bioactive compounds which show antioxidant activity. The plant extract might be helpful in preventing and slowing the progress of various oxidative stress induced diseases. It might be useful for the development of newer and more 
potent natural antioxidants. The methanol extract of Morchella esculenta exhibited significant antioxidant activity compare to standard ascorbic acid. The results of the present study suggest that Morchella esculenta could be a potential source of natural antioxidant that could have great importance as therapeutic agents in preventing or slowing the progress of oxidative stress related degenerative diseases. These results might be helpful for providing the platform for researchers and pharmaceutical companies for the development of precious medicines which will be helpful for treatment of oxidative stress generated diseases.

\section{ACKNOWLEDGMENT}

The authors express gratitude to Dept. of Botany Govt. MVM and CMBT Bhopal for their facility and kind support for the present work.

\section{REFERENCES}

[1]. Prasad, P. K., Chauhan, L.S., Kandari, R.K., Maikhuri, A., Purohit, P. Bhatt and Rao, K. S. (2002) Morchella esculenta (Guchhi): Need for scientific intervention for its cultivation in Central Himalaya, Curr. Sci. 82(9): 1098 - 1100.

[2]. Lakhanpal, T.N., Shad, O. and Rana, M. (2010) Biology of Indian Morels. I. K. International Publishing House, New Delhi.

[3]. Reis, F.S., Stojkovic, D., Sokovic, M., Glamoclija, J., Ciric, A., Barros, L., and Ferreira, I.C.F.R. (2012). Chemical characterization of Agaricus bohusii, antioxidant potential and antifungal preserving properties when incorporated in cream cheese. Food Research International. 48: 620-626.

[4]. Leal, A.R., Barros, L., Barreira, J.C.M., Sousa, M.J., Martins, A., Santos-Buelga, C., and Ferreira, I.C.F.R. (2013). Portuguese wild mushrooms at the "Pharma-Nutrition" interface: Nutritional characterization and antioxidant properties. Food Research International. 50: 1-9.

[5]. Sachindra, N. M., M. K. W. A. Airanthi, M. Hosokawa and K. Miyashita, 2010. Radical scavenging and singlet oxygen quenching activity of extracts from Indian seaweeds. Journal of Food Science and Technology, 47: 94-99.

[6]. Kosanic, M., B. Rankovic and J. Vukojevic, 2011. Antioxidant properties of some lichen species. Journal of Food Science and Technology, 48: 584-590.

[7]. Zhang, W. M., B. L. Lin Han and H. D. Zhang, 2009. Antioxidant activities of extracts from Areca (Areca catectu L.) flower, husk and seed. Electronic Journal of Environmental, Agricultural and Food Chemistry, 8: 740-748.

[8]. Oyetayo, V. O., C. H. Dong and Y. J. Yao, 2009. Antioxidant and Antimicrobial Properties of Aqueous Extract from Dictyophora indusiata. The Open Mycology Journal, 3: 20-26.

[9]. Mau, J. L., C. N. Chang, S. J. Huang and C. C. Chen, 2004. Antioxidant properties of methanolic extract from Grifola frondosa, Morchella esculenta and Termitomyces albuminosus mycelia. Food Chemistry, 87: 111-118.

[10]. Barros, L., R. C. Calhelha, J. A. Vaz, I. C. F. R. Ferreira, P. Baptista and L. M. Estevinho, 2007. Antimicrobial activity and bioactive compounds of Portuguese wild edible mushrooms methanolic extracts. European Food Research and Technology, 225: 151-156.

[11]. Ferreira, I. C. F. R., P. Baptista, M. Vilas-Boas and L. Barros, 2007. Free-radical scavenging capacity and reducing power of wild edible mushrooms from northeast Portugal: individual cap and stipe activity. Food Chemistry, 100: 1511-1516.
[12]. Jagetia G.C, Rao S.K, Baliga M.S, Babu K.S. The Evaluation of Nitric Oxide Scavenging Activity of Certain Herbal Formulations in vitro: A Preliminary Study. Phytother. Res. 18: 561-565, 2004.

[13]. Vriesman M.F, Haenen G.R, Westerveld G.J, Paquay J.B, Voss H.P, Bast A. A method for measuring nitric oxide radical scavenging activity. Scavenging properties of sulfur-containing compounds. Pharm World Sci. 19(6): 283-286, 1997.

[14]. Hagerman A.E, Riedl K.M, Jones G.A, Sovik K.N, Ritchard N.T, Hartzfeld P.W. 1998. High molecular weight plant poly-phenolics (tannins) as biological antioxidants. J Agric and Food Chem. 46: 1887-1892, 1998.

[15]. Nabavi SM, Ebrahimzadeh M.A, Nabavi S.F, Hamidinia A, Bekhradnia A.R. Determination of antioxidant activity, phenol and flavonoids content of Parrotia persica Mey. Pharmacology online 2: 560-567, 2008.

[16]. Gulati K, Ray A, Masood A, Vijayan V.K. Involvement of nitric oxide (NO) in the regulation of stress susceptibility and adaptation in rats. Indian J Exp Biol. 44:809-815, 2006.

\section{AUTHORS PROFILE}

D. R. Baba and P. M. Junaid pursed M. Sc. in Botany and presently pursuing Ph.D. in Botany at Barkatullah University Bhopal. Mrs F. Khan is currently working as Professor in Department of Botany at Govt. College Nasrullagunj Sehore M. P. Mrs R. Singh is currently working as Professor in Department of Botany at Govt. Motilal Vigyan Mahavidyalaya Bhopal. The authors have published more than 20 research papers in reputed international journals. The main research work is based on the mycology especially the Mushrooms. 